\title{
VITIMIZAÇÃO E SENTIMENTO DE INSEGURANÇA NO BRASIL EM 2010: TEORIA, ANÁLISE E CONTEXTO
}

\author{
Doriam Borges ${ }^{1}$
}

\begin{abstract}
RESUMO
Este estudo foi elaborado para analisar a relação entre as taxas de vitimização e 0 sentimento de insegurança através dos dados de uma pesquisa nacional, que foram coletados para avaliar a prevalência da vitimização no Brasil e as taxas específicas de crimes, bem como para estudar o perfil demográfico das vítimas. Os resultados de quatro regressões logísticas mostraram que o sentimento de insegurança se relaciona positivamente com a vitimização, além disso, variáveis demográficas quando incluídas no modelo (sexo, educação, idade e Grandes Regiões) como preditoras do sentimento de insegurança, apresentam efeitos interessantes. Ainda assim, ressaltamos que os resultados indicam que 0 sentimento de insegurança não deve ser interpretado como uma resposta irracional ou injustificada, mas como uma reação às crenças de perigo.
\end{abstract}

Palavras-chave: Pesquisa de vitimização. Medo do crime. Sentimento de insegurança.

\section{VICTIMIZATION AND FEELINGS OF INSECURITY IN BRAZIL IN 2010: THEORY, ANALYSIS AND CONTEXT}

ABSTRACT

This study was developed to examine the relationship between the rates of victimization and the feeling of insecurity through data from a national survey, which were collected to assess the prevalence of victimization in Brazil and specific rates of crimes, as well as

\footnotetext{
${ }^{1}$ Professor do Programa de Pós-Graduação em Ciências Sociais da Universidade Estadual de Rio de Janeiro, Brasil. doriamb@gmail.com
} 
to study the demographic profile of victims. The results of four logistic regressions showed that the feeling of insecurity is positively related to victimization, furthermore, when demographic variables are included in the model (gender, education, age and Major Regions) as predictors of the feeling of insecurity, there are interesting effects. Still, we emphasize that the results indicate that the feeling of insecurity should not be interpreted as an irrational or unreasonable response, but as a reaction to the beliefs of danger.

Keywords: Victimization research. Fear of crime. Feeling of insecurity.

\section{INTRODUÇÃO}

criminalidade e a violência são temas de forte conteúdo político, além de serem
objetos de constante pressão social e também temas de destaque entre os problemas parte da agenda de muitos políticos, estudiosos e representantes da sociedade civil. Nesse contexto, a segurança pública se tornou parte fundamental do discurso político vigente, quer seja ele, municipal, estadual ou federal. Estas novas práticas estão ligadas aos efeitos que a criminalidade urbana e a violência exercem sobre a sociedade. Assim, as relações que a população estabelece com o crime têm se constituído, ao longo do tempo, como um importante elemento para a melhor compreensão da sociedade. A vida urbana tem sido definida pelo paradoxo de um ideal civilizatório e pelo sentimento do medo. Os indivíduos se tornaram reféns do risco da violência, e têm sido obrigados a mudar suas rotinas, deixando de frequentar alguns lugares ou mesmo de sair de casa, uma vez que a reclusão à intimidade do lar passa a ser uma atitude recomendada. A saída comunicada a familiares e amigos, como precaução, também se incorporou à rotina dos indivíduos, criando uma espécie de rede de vigilância solidária durante o percurso destes. Tal realidade tem conduzido os governantes do nosso país a estabelecerem metas de redução da violência, visando melhorar as condições de vida das pessoas.

Mas, como é possível mensurar este fenômeno e os principais efeitos causados pela experiência direta e indireta dos indivíduos com a violência? Para responder esta pergunta, a Pesquisa sobre as Condições de Vida e o Acesso das Pessoas a Serviços Públicos aqui na sua Região/PCVAPSP-2010² incluiu em seu questionário um bloco

\footnotetext{
${ }^{2}$ Este artigo foi elaborado com base nos resultados de um survey realizado pelo IUPERJ, atual Instituto de Estudos Sociais e Políticos da Universidade do Estado do Rio de Janeiro (IESP-UERJ), em parceria com 0 IBOPE em junho de 2010. A pesquisa baseou-se na aplicação de 3.612 entrevistas pessoais e domiciliares a uma amostra nacional da população maior de 16 anos, estratificada com alocação proporcional à
} 
voltado para a obtenção de informações sobre a população em relação a aspectos ligados à mensuração da vitimização e do sentimento de insegurança (FIGUEIREDO, SALLES, RIBEIR0 e BORGES, 2010). Este trabalho, portanto, tem por objetivo a apresentação dos principais dados encontrados na pesquisa sobre essas temáticas. Algumas das mais importantes variáveis estruturadas no questionário foram incluídas neste artigo a fim de exibir um panorama da percepção da população ante a situação da violência e da criminalidade no Brasil, e sua relação com a vitimização e o sentimento de insegurança.

\section{PreValÊNCIA DA VITIMIZAÇÃo No BRASIL EM 2010 E O PERFIL DAS VÍTIMAS}

Durante as últimas décadas, a violência e o risco de se tornar vítima de um crime têm sido temas frequentemente abordados em diversos estudos sociológicos e criminológicos. No Brasil, as informações mais utilizadas para o estudo da violência advêm de duas fontes oficiais: as estatísticas da polícia e da saúde. Estas fontes são claramente importantes no desenvolvimento, monitoramento e avaliação de políticas públicas, e projetam de modo coerente as taxas na área da violência. Entretanto, ambas possuem algumas distorções e podem ser consideradas incompletas, desse modo, é muito difícil conhecer a quantidade de crimes que ocorrem na sociedade, já que essas são apenas uma fração do total de crimes. Como uma tentativa de resolver este problema, foi desenvolvida uma ferramenta para estimar o número total de crimes ocorridos: as pesquisas de vitimização. A partir deste tipo de pesquisa é possível identificar as taxas de subnotificação das ocorrências, razões para a subnotificação ou o que pode ajudar no desenvolvimento de estratégias de correção do problema.

Neste sentido, a pesquisa de vitimização é um instrumento valioso tanto para medir o crime como para estimar com maior precisão o perfil das vítimas, bem como, avaliar o impacto do fato delituoso na vida dos indivíduos, o que de outra forma, através dos registros de ocorrência, seria improvável. Ademais, as perguntas desse tipo de pesquisa procuram obter informações sobre o sentimento de insegurança. Conforme salientado anteriormente, a Pesquisa sobre as Condições de Vida e o Acesso das Pessoas a Serviços Públicos aqui na sua Região incluiu um bloco sobre vitimização e sentimento de insegurança.

Entretanto, devemos ter cautela ao analisar essas perguntas, pois existem dois métodos de mensuração deste tema: (1) um que 0 entrevistado responde sobre as ocorrências criminais das quais foi vítima; e, (2) outro, em que qualquer morador (respondente proxy) responde perguntas sobre si mesmo e pode dar informações sobre

população de cada estrato. Essa pesquisa foi coordenada pela Dra Argelina Figueiredo, a quem agradeço os comentários, as críticas e as sugestões. 
os demais moradores do domicílio. Segundo Piquet (1999), as diferenças quanto ao método de entrevista são o principal fator a ser levado em conta na comparação dos resultados com outras pesquisas. As taxas de vitimização em pesquisas em que 0 entrevistado responde apenas sobre a sua experiência individual são aproximadamente 2,8 vezes maiores do que as taxas das pesquisas com pessoas que respondem sobre si mesmas e sobre os outros moradores do domicílio (PIQUET, 1999). Esses resultados se devem ao fato de que muitos eventos de vitimização não são conhecidos por todos os membros do domicílio.

As perguntas aplicadas pela pesquisa e utilizadas neste trabalho mensuram a experiência de vitimização seguindo o método de perguntas em que os entrevistados respondem por todos do domicílio. Em resumo, as taxas de vitimização são calculadas com base em informações prestadas por moradores que podem não estar diretamente envolvidos na ocorrência.

Nesta seção, serão apresentados alguns dados sobre vitimização, além de um perfil simples da vítima. No Gráfico 1 podemos verificar que a estimativa da taxa de vitimização nos últimos 12 meses é de 14\% para o Brasil.

Gráfico 1 - Taxa de vitimização nos últimos 12 meses - Brasil

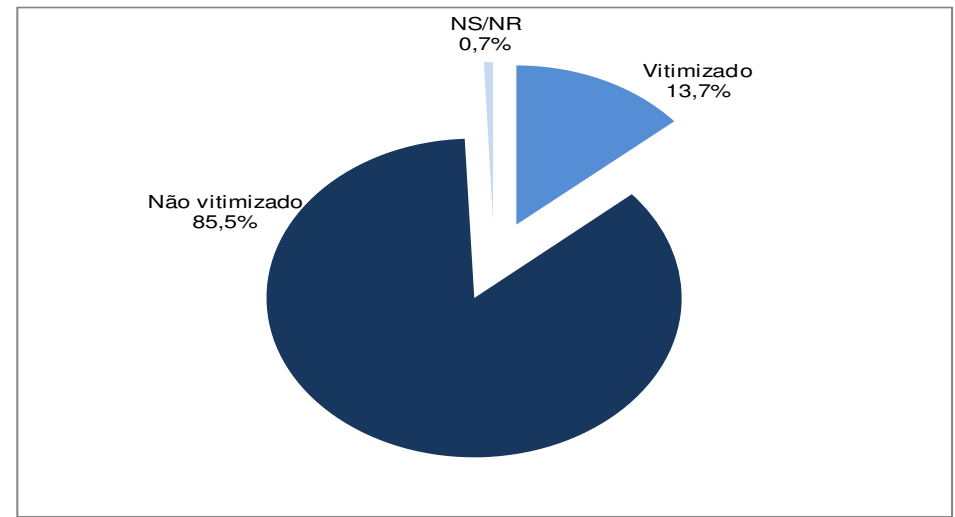

Fonte: Pesquisa sobre as Condições de Vida e o Acesso das Pessoas a Serviços Públicos aqui na sua Região (FIGUEIREDO, SALLES, RIBEIR0 e BORGES, 2010).

As taxas de vitimização segundo a condição do município podem ser examinadas no Gráfico 2. Analisando este gráfico podemos perceber que as capitais possuem uma taxa de vitimização de 20,6\%, significativamente maior do que as encontradas para os municípios da periferia $(15,3 \%)$ e do interior $(10,7 \%)$. Esses resultados seguem na 
mesma direção dos estudos que afirmam que as taxas de vitimização são mais altas nos centros urbanos (COHEN; FELSON, 1979; COOK, 1986).

Gráfico 2 - Taxa de vitimização nos últimos 12 meses, segundo a condição do município.

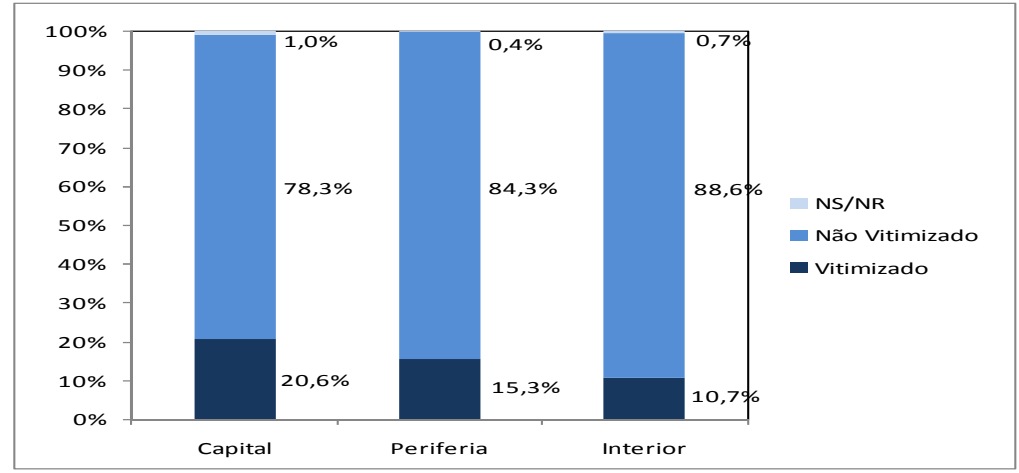

(*) Diferença estatisticamente significante com uma probabilidade de $95 \%$.

Fonte: Pesquisa sobre as Condições de Vida e o Acesso das Pessoas a Serviços Públicos aqui na sua Região (FIGUEIREDO, SALLES, RIBEIR0 e BORGES, 2010).

A prevalência de crimes é um indicador importante que pode ser elaborado a partir de pesquisas como essa. Este indicador é definido pela proporção de pessoas que tiveram a experiência de vitimização por tipo de crime em uma determinada população e em um momento temporal específico. Nesta pesquisa foi perguntado sobre a experiência de vitimização nos últimos 12 meses. Entre os 18 tipos de delitos abordados, os crimes contra o patrimônio - furtos e roubos - foram claramente os de maior incidência. Sob o risco de parecer tautológico, é preciso insistir que os crimes contra 0 patrimônio ocorrem onde existe patrimônio para ser subtraído. Trata-se de crimes "opportunity driven" em contraste com os crimes contra a pessoa, que são "poverty driven" 
Gráfico 3 - Taxa de vitimização nos últimos 12 meses por tipo de delito (Prevalência)

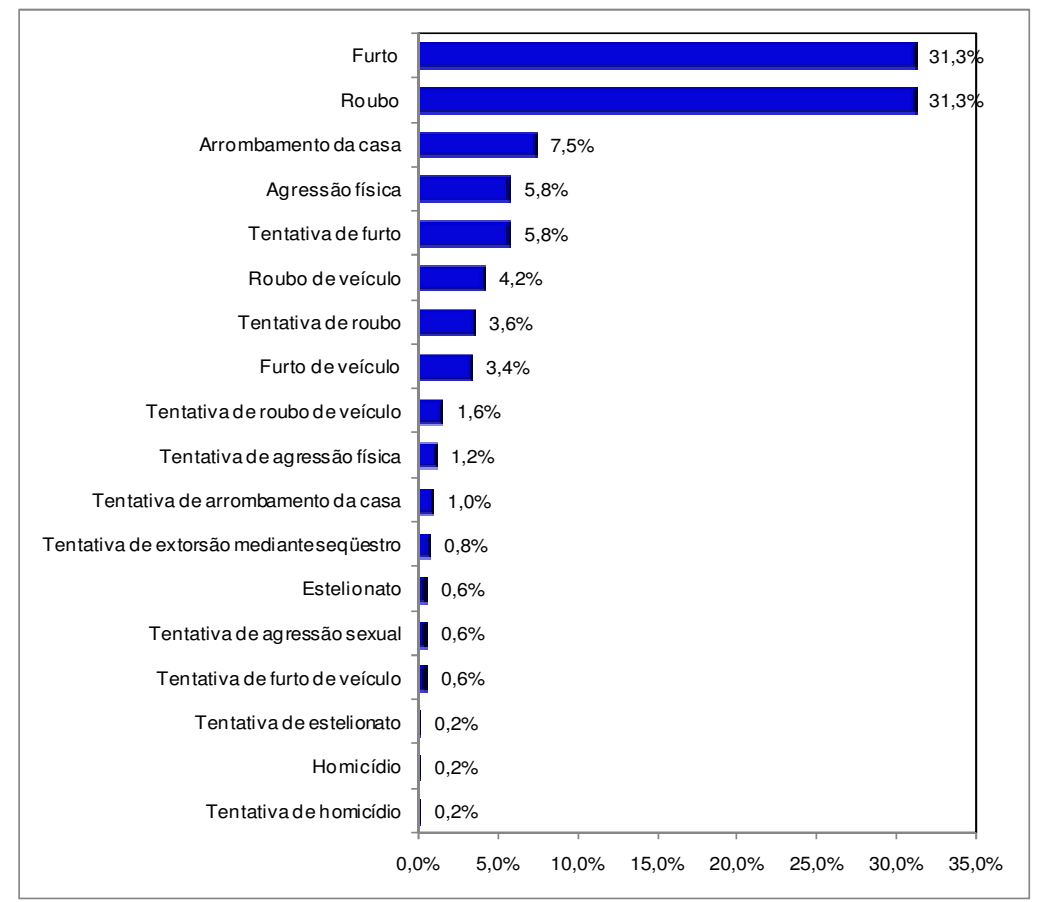

Fonte: Pesquisa sobre as Condições de Vida e o Acesso das Pessoas a Serviços Públicos aqui na sua Região (FIGUEIREDO, SALLES, RIBEIR0 e BORGES, 2010).

Algumas pesquisas analisam os efeitos de características demográficas e sociais sobre a vitimização, demonstrando que indivíduos que são, por exemplo, homens, jovens, solteiros ou moradores de zonas urbanas sofrem um risco maior de vitimização do que aqueles que pertencem a outros grupos (BEATO, PEIXOTO; ANDRADE, 2004). 
Tabela 1 - Taxa de vitimização nos últimos 12 meses, segundo perfil

\begin{tabular}{|c|c|c|c|c|c|}
\hline & Vitimizado & Não Vitimizado & NS/NR & Total & \\
\hline \multicolumn{6}{|c|}{ Sexo } \\
\hline Masculino & $246 \quad 14,3 \%$ & $1.467 \quad 85,1 \%$ & $10 \quad 0,6 \%$ & 1.723 & $100 \%$ \\
\hline Feminino & $250 \quad 13,2 \%$ & $1.623 \quad 85,9 \%$ & $16 \quad 0,8 \%$ & 1.889 & $100 \%$ \\
\hline \multicolumn{6}{|c|}{ Faixa Etária $\left(^{*}\right)$} \\
\hline 16 a 17 anos & $11 \quad 13,6 \%$ & $70 \quad 86,4 \%$ & $0,0,0 \%$ & 81 & $100 \%$ \\
\hline 18 a 24 anos & $119 \quad 17,9 \%$ & $541 \quad 81,5 \%$ & $4 \quad 0,6 \%$ & 664 & $100 \%$ \\
\hline 25 a 29 anos & $77 \quad 16,9 \%$ & $378 \quad 82,9 \%$ & $10,2 \%$ & 456 & $100 \%$ \\
\hline 30 a 39 anos & $114 \quad 14,6 \%$ & $66184,5 \%$ & $7 \quad 0,9 \%$ & 782 & $100 \%$ \\
\hline 40 a 49 anos & $90 \quad 12,9 \%$ & $603 \quad 86,1 \%$ & $\begin{array}{ll}7 & 7,0 \% \\
\end{array}$ & 700 & $100 \%$ \\
\hline 50 a 69 anos & $76 \quad 9,5 \%$ & $715 \quad 89,8 \%$ & $50,6 \%$ & 796 & $100 \%$ \\
\hline 70 anos ou mais & $96,8 \%$ & $122 \quad 91,7 \%$ & $2 \quad 1,5 \%$ & 133 & $100 \%$ \\
\hline \multicolumn{6}{|c|}{ Escolaridade } \\
\hline Analfabeto & $6 \quad 3,1 \%$ & $96,4 \%$ & $\begin{array}{ll}1 & 0,5 \% \\
\ldots\end{array}$ & 194 & $100 \%$ \\
\hline $\begin{array}{l}\text { Sabe ler/escrever, mas não } \\
\text { cursou escola }\end{array}$ & $4 \quad 12,5 \%$ & $87,5 \%$ & $0 \quad 0,0 \%$ & 32 & $100 \%$ \\
\hline Ensino Fundamental Incompleto & $135 \quad 10,9 \%$ & $88,6 \%$ & $\begin{array}{ll}7 & 0,6 \% \\
\end{array}$ & 1244 & $100 \%$ \\
\hline Ensino Fundamental Completo & $59 \quad 15,6 \%$ & $83,6 \%$ & $3 \quad 0,8 \%$ & 377 & $100 \%$ \\
\hline Ensino Médio Incompleto & $56 \quad 16,5 \%$ & $82,6 \%$ & $3 \quad 0,9 \%$ & 339 & $100 \%$ \\
\hline Ensino Médio Completo & $154 \quad 16,9 \%$ & $82,0 \%$ & $10 \quad 1,1 \%$ & 911 & $100 \%$ \\
\hline Superior Incompleto & $41 \quad 16,0 \%$ & $83,6 \%$ & $1 \quad 0,4 \%$ & 256 & $100 \%$ \\
\hline Superior Completo & $41 \quad 15,8 \%$ & $83,8 \%$ & $10,4 \%$ & 259 & $100 \%$ \\
\hline \multicolumn{6}{|c|}{ Faixa de Renda Familiar per capita em Salários Mínimos (SM) } \\
\hline Menos de $1 / 2 \mathrm{SM}$ & $137 \quad 12,6 \%$ & $87,4 \%$ & $\begin{array}{ll}0 & 0,0 \% \\
0\end{array}$ & 1.084 & $100 \%$ \\
\hline $1 / 2$ a $1 \mathrm{SM}$ & $151 \quad 13,2 \%$ & $86,8 \%$ & $0,0 \%$ & 1.147 & $100 \%$ \\
\hline $1 \mathrm{a} 2 \mathrm{SM}$ & $142 \quad 14,8 \%$ & $85,2 \%$ & $0,0 \%$ & 958 & $100 \%$ \\
\hline 3 SM ou mais & $27 \quad 17,9 \%$ & $82,1 \%$ & $0,0 \%$ & 151 & $100 \%$ \\
\hline \multicolumn{6}{|c|}{ Cor } \\
\hline Branca & $215 \quad 13,7 \%$ & $85,6 \%$ & $0,8 \%$ & 1.575 & $100 \%$ \\
\hline Preta & $71 \quad 13,5 \%$ & $85,5 \%$ & $1,0 \%$ & 525 & $100 \%$ \\
\hline Parda & $201 \quad 14,1 \%$ & $85,3 \%$ & $0,6 \%$ & 1.423 & 100\%" \\
\hline \multicolumn{6}{|c|}{ Estado Civil (*) } \\
\hline Está solteiro(a) & $185 \quad 17,0 \%$ & $82,4 \%$ & $0,6 \%$ & 1.087 & $100 \%$ \\
\hline Está casado(a) & $189 \quad 12,5 \%$ & $86,8 \%$ & $0,7 \%$ & 1.510 & $100 \%$ \\
\hline $\begin{array}{l}\text { Está morando junto com o(a) } \\
\text { companheiro(a) }\end{array}$ & $72 \quad 12,3 \%$ & $86,7 \%$ & $1,0 \%$ & 587 & $100 \%$ \\
\hline $\begin{array}{l}\text { Está separado(a)/ divorciado(a)/ } \\
\text { desquitado }\end{array}$ & $36 \quad 14,6 \%$ & $84,2 \%$ & $1,2 \%$ & 247 & $100 \%$ \\
\hline É viúvo(a) & $14 \quad 8,0 \%$ & $91,5 \%$ & $0,6 \%$ & 176 & $100 \%$ \\
\hline
\end{tabular}

(*) Diferença estatisticamente significante com uma probabilidade de $95 \%$.

Fonte: Pesquisa sobre as Condições de Vida e o Acesso das Pessoas a Serviços Públicos aqui na sua Região (Figueiredo, Salles, Ribeiro e Borges, 2010).

Segundo alguns autores, as diferenças do sexo da vítima podem contribuir significativamente para as variações das taxas de vitimização em função das diferenças 
de comportamento entre os homens e as mulheres. Nessa perspectiva, os homens apresentam maiores probabilidades de serem vitimizados devido a sua maior exposição, utilizando como referência o argumento da teoria das atividades rotineiras (FELSON; COHEN, 1980) $)^{3}$. Em contrapartida, as mulheres podem ser vítimas mais atrativas em função de sua menor capacidade de reação aos agressores. Surpreendentemente, analisando os resultados da pesquisa, não encontramos uma diferença significativa entre vitimização e sexo do entrevistado. Vale ressaltar que o perfil utilizado nesta análise não se refere diretamente ao da pessoa vitimada, mas do morador que respondeu ao questionário, que pode ter sofrido o delito ou pode morar com alguém que tenha vivenciado a experiência de vitimização.

Além das diferenças do sexo das vítimas o momento do ciclo de vida no qual o indivíduo se encontra também foi objeto de interesse de estudo na pesquisa de vitimização, porém ao contrário das diferenças de sexo das vítimas, apresentou uma forte relação com os riscos de vitimização. Os resultados mostraram que as pessoas nas etapas iniciais do ciclo de vida e os mais idosos apresentam menor exposição; e menor probabilidade de frequentar lugares públicos - a proporção de tempo que passam em família é maior e suas interações sociais são limitadas.

Já conforme podemos visualizar na Tabela 1, o grupo de pessoas com idade entre 18 e 29 anos é o que apresenta maiores taxas de vitimização (do próprio entrevistado ou de outro morador do domicílio). Supondo que foi o entrevistado a pessoa vitimizada, podemos atribuir aos fatores "exposição", "menor capacidade de proteção" e "proximidade entre vítima e agressor" a explicação para os resultados (FELSON; COHEN, 1980). Indivíduos mais jovens em sua maioria são solteiros, frequentam mais lugares públicos sem se preocupar muito com sua própria proteção. 0 percentual de pessoas que disse ter algum morador no domicílio que tenha sido vitimizado nos últimos 12 meses vai diminuindo à medida que consideramos as faixas etárias mais elevadas dos entrevistados, o que pode estar indicando a relação entre vitimização e o fator exposição.

Indivíduos com mais escolaridade provavelmente auferem mais rendas do que os menos escolarizados, e são mais atrativos, pois exibem maior retorno esperado pelo crime, particularmente no caso de delitos com motivação econômica. Na Tabela 1, podemos averiguar que a vitimização de algum morador do domicílio incide mais entre os indivíduos com escolaridade mais elevada, mostrando a importância do fator atratividade. Em contrapartida, vale ressaltar que, em geral, a vitimização por agressão

\footnotetext{
${ }^{3} 0$ modelo teórico das atividades rotineiras foi proposto por Cohen e Felson (1979). Nele, uma ocorrência criminal necessita da composição formada por um indivíduo motivado a cometer o crime, uma vítima para esse crime e a falta de guardiões capazes de deter a vitimização. Posteriormente, o modelo teórico das atividades rotineiras foi ampliado por Cohen et al. (1981), que introduziu mais duas dimensões para explicar os riscos de vitimização: exposição e atratividade do alvo potencial.
} 
incide mais em indivíduos menos escolarizados e com rendas mais baixas, indicando a importância da capacidade de proteção e do efeito socializador da educação.

A literatura mostra que a renda pode ser relevante na determinação da probabilidade de vitimização de um indivíduo. A renda é um tipo de reflexo da posição do indivíduo na estrutura econômica da sociedade, que está relacionada ao fator de atratividade da vítima, ou seja, as pessoas com renda mais alta oferecem lucros potenciais mais elevados para os criminosos. Analisando a Tabela 1 podemos perceber que, não existem diferenças estatisticamente significativas na experiência de vitimização de algum morador do domicílio, segundo a renda familiar per capita em salários mínimos.

Outro aspecto analisado na pesquisa foi a da cor das vítimas. 0 Brasil, apesar de ser um país com altos índices de desigualdade racial, apresenta baixos níveis de segregação espacial por cor o que leva essa variável a não capturar bem 0 efeito de proximidade e proteção, atribuídas a ela pela literatura. Em sociedades racialmente segregadas, a mobilidade residencial dos indivíduos tende a ser limitada, e indivíduos de grupos minoritários apresentam uma propensão cultural a permanecer em bairros fortemente heterogêneos, que, por sua vez, pode aumentar as chances de proximidade com os potenciais agressores e a diminuição da capacidade de proteção. Por outro lado, se a população não está segregada racialmente, a cor do indivíduo não terá efeito na determinação das probabilidades de vitimização. Os resultados apresentados na Tabela 1 confirmam essa hipótese, ou seja, não existe diferença estatisticamente significativa entre a cor autodeclarada do indivíduo e as taxas de vitimização dos moradores do domicílio.

A relação esperada entre estado civil e os riscos de vitimização está diretamente ligada com o fator de exposição. Normalmente, se espera que os solteiros apresentem probabilidades mais elevadas de vitimização do que os casados. Apesar de a vitimização se referir à experiência de algum morador do domicílio, encontramos na Tabela 1 resultados que confirmam esse pressuposto. A maior taxa de vitimização está entre os indivíduos solteiros (17\%), seguido dos separados / divorciados / desquitados (14,6\%). Esses indivíduos estão mais expostos, pois tendem a passar menos tempo com suas famílias, por isso apresentam maiores riscos de vitimização.

\section{FATORES EXPLICATIVOS DO SENTIMENTO DE INSEGURANÇA NO BRASIL EM 2010}

0 sentimento de insegurança e o medo do crime têm assumido, atualmente, uma relevância cada vez maior na sociedade brasileira, uma vez que aspectos como 0 aumento do crime, sua utilização política, o discurso social e a percepção de perda de 
controle têm atingido proporções significativas. Além disso, o sentimento de insegurança e o medo do crime afetam mais indivíduos que o problema específico da criminalidade, considerando que abrange um universo muito maior de pessoas.

Segundo Ferraro (1995), a mensuração do medo do crime deve ser desempenhada com cautela, pois diz respeito a um fenômeno de caráter subjetivo, que envolve a reação emocional de um indivíduo. Após analisar diferentes estudos, Ferraro (1995) percebeu que as pesquisas costumam utilizar, principalmente, dois tipos de perguntas:

1. primeiro tipo se refere à pergunta utilizada na National Crime Survey (NCS): "How safe do you feel or would you feel being out alone in your neighborhood at night?" [o mesmo também se pergunta sobre "during the day?"];

2. segundo tipo de pergunta é a utilizada na General Social Survey (GSS): "Is there any area right around here - that is, within a mile - where you would be afraid to walk alone at night?".

Para 0 autor, na realidade, essas pesquisas estão mensurando a percepção do risco de vitimização. Segundo DuBow et al. (1979 apud WARR, 1994), a percepção do risco refere-se à avaliação do indivíduo em relação às taxas de crime e à probabilidade de vitimização. A maioria das pesquisas brasileiras que possuem perguntas para medir 0 medo do crime utiliza as perguntas que medem a percepção do risco, normalmente classificadas como sentimento de insegurança ao andar pelas ruas de uma determinada área durante o dia e durante a noite (BORGES, 2011). Neste trabalho, utilizaremos uma medida do medo do crime que representa a percepção do risco de vitimização, através de quatro perguntas: sentimento de insegurança no bairro ou na cidade, durante o dia ou à noite.

Tendo ou não sido vítimas de crimes nos últimos anos, os brasileiros sentem-se bastante inseguros, a mercê do crescimento da violência nas últimas três décadas. Do total da população estimada, $37 \%$ se sente insegura no bairro de moradia durante 0 dia e $59 \%$ tem o mesmo sentimento durante a noite. Por outro lado, 74\% das pessoas se sentem inseguras na cidade durante a noite. Pesquisas sugerem que as pessoas se sentem mais seguras em locais conhecidos e próximos de suas residências (BORGES, 2011).

Dando continuidade à análise, devemos levar em consideração o horário do dia na avaliação da segurança. A influência da dimensão dia ou noite é significativa no sentimento de insegurança no próprio bairro e na cidade (Gráfico 4). No bairro de moradia o percentual de pessoas que se sentem inseguras passa de $37 \%$ durante 0 dia para 59\% durante a noite, e na avaliação do sentimento de insegurança na cidade, essa mudança é de 57\% durante o dia, para 74\% à noite. 
Gráfico 4 - Sentimento de insegurança durante o dia e à noite por local

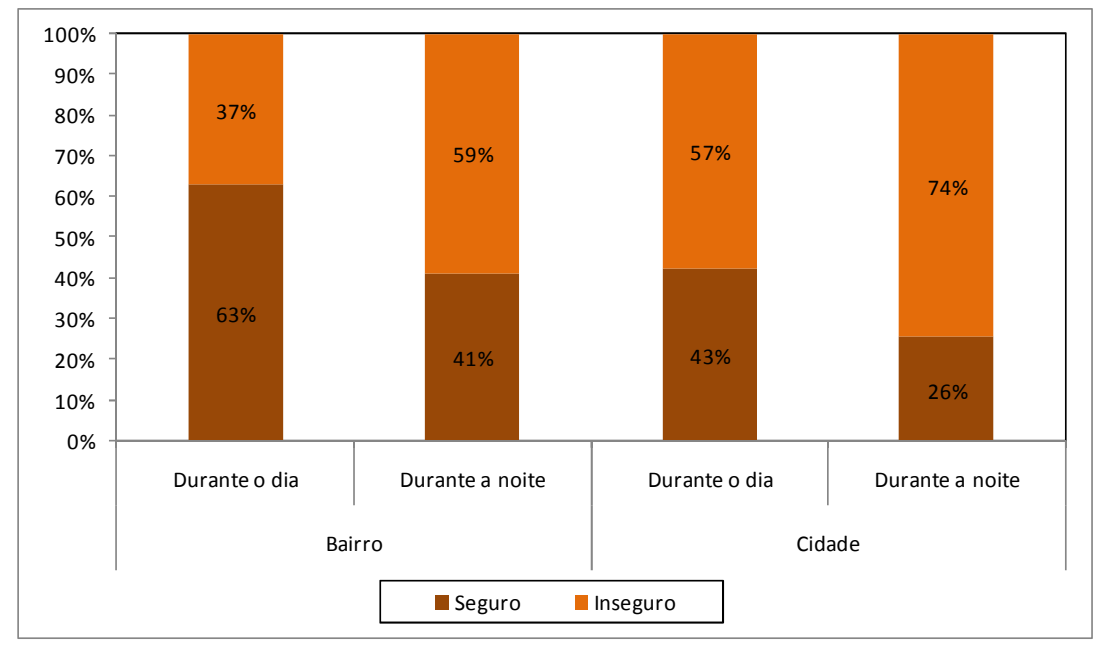

Fonte: Pesquisa sobre as Condições de Vida e o Acesso das Pessoas a Serviços Públicos aqui na sua Região (FIGUEIREDO, SALLES, RIBEIR0 e BORGES, 2010).

Uma hipótese intuitiva nos diz que o sentimento de insegurança varia com a violência e a criminalidade, ou seja, onde há mais crime e mais violência há mais medo e mais sentimento de insegurança. Porém, muitos autores já demonstram que a associação entre taxas reais de criminalidade, por um lado, e o sentimento de insegurança, por outro, é menos íntima do que a intuição sugere (CONKLIN, 1975; DUBOW et al., 1979; HALE, 1996; OVIEDO; RODRÍGUEZ, 1999).

Considerando que as capitais apresentam taxas mais altas de violência do que as cidades da periferia e do interior, nesta ordem, então, analisando o Gráfico 5, podemos acreditar na existência de alguma relação entre as altas taxas de vitimização e 0 sentimento de insegurança. Os moradores das capitais se sentem mais inseguros durante o dia e à noite na cidade e no bairro de moradia do que os municípios de periferia e do interior. 
Gráfico 5 - Sentimento de insegurança durante o dia e à noite por local, segundo a condição do município

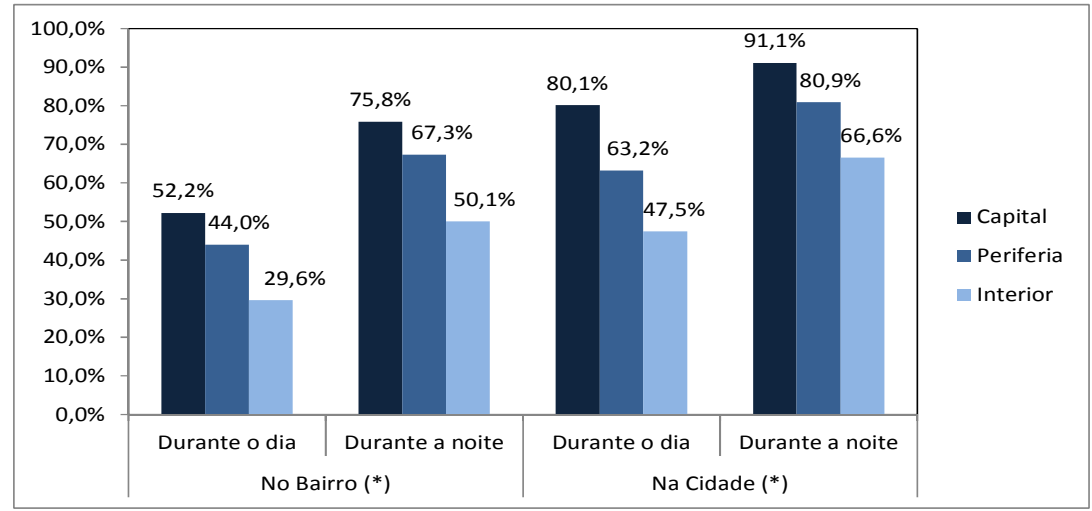

(*) Diferença estatisticamente significante com uma probabilidade de $95 \%$.

Fonte: Pesquisa sobre as Condições de Vida e o Acesso das Pessoas a Serviços Públicos aqui na sua Região (FIGUEIREDO, SALLES, RIBEIRO E BORGES, 2010).

Gênero é uma das principais variáveis tanto no estudo da vitimização quanto nas análises do sentimento de insegurança. Autores têm afirmado que as mulheres se sentem mais inseguras que os homens (WARR, 1984; STAFFORD; GALLE, 1984). Avaliando a diferença de gênero no sentimento de insegurança no Brasil, verificamos que os resultados confirmam esta hipótese: enquanto $55,6 \%$ dos homens sentem-se inseguros no bairro de moradia durante a noite, $61,4 \%$ das mulheres possuem esse mesmo sentimento (Gráfico 6). 
Gráfico 6 - Sentimento de insegurança durante o dia e à noite por local, segundo sexo

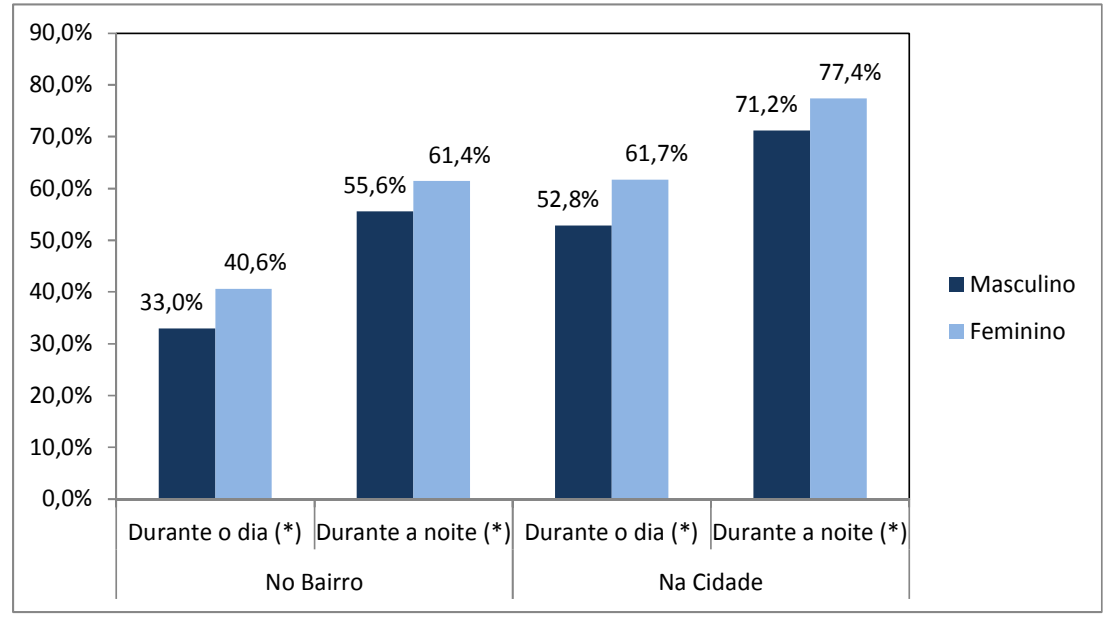

(*) Diferença estatisticamente significante com uma probabilidade de $95 \%$.

Fonte: Pesquisa sobre as Condições de Vida e o Acesso das Pessoas a Serviços Públicos aqui na sua Região (FIGUEIREDO, SALLES, RIBEIR0 e BORGES, 2010).

Outra variável-chave que possui efeitos sobre o sentimento de insegurança é a idade. Jovens, sobretudo com idade entre 16 e 24 anos, são os que possuem maior risco de vitimização. Entretanto os mais idosos são os que apresentam mais medo. Nesta pesquisa, os jovens com idade entre 16 e 17 anos se mostraram menos inseguros que os outros grupos etários (Tabela 2). Os mais velhos (70 anos ou mais) não foram os mais inseguros em nenhuma das categorias de insegurança (bairro de moradia e cidade de dia e à noite), apesar da tendência de crescimento do percentual de insegurança conforme aumenta a faixa etária, sobretudo no que se refere a cidade durante a noite. 
Tabela 2 - Sentimento de insegurança durante o dia e à noite por local, segundo a faixa etária

\begin{tabular}{|c|c|c|c|c|c|c|c|c|c|c|c|c|}
\hline \multicolumn{13}{|c|}{ No Bairro } \\
\hline & \multicolumn{6}{|c|}{ Durante o dia $\left(^{*}\right)$} & \multicolumn{6}{|c|}{ Durante a noite $(*)$} \\
\hline & \multicolumn{2}{|c|}{ Seguro } & \multicolumn{2}{|c|}{ Inseguro } & \multicolumn{2}{|c|}{ Total } & \multicolumn{2}{|c|}{ Seguro } & \multicolumn{2}{|c|}{ Inseguro } & \multicolumn{2}{|c|}{ Total } \\
\hline 16 a 17 anos & & $64,2 \%$ & 29 & $35,8 \%$ & 81 & $100 \%$ & 38 & $46,9 \%$ & 43 & $53,1 \%$ & 81 & $100 \%$ \\
\hline 18 a 24 anos & 449 & $67,8 \%$ & 213 & $32,2 \%$ & 662 & $100 \%$ & 255 & $38,4 \%$ & 409 & $61,6 \%$ & 664 & $100 \%$ \\
\hline 25 a 29 anos & 282 & $61,8 \%$ & 174 & $38,2 \%$ & 456 & $100 \%$ & 172 & $37,7 \%$ & 284 & $62,3 \%$ & 456 & $100 \%$ \\
\hline 30 a 39 anos & 454 & $58,1 \%$ & 327 & $41,9 \%$ & 781 & $100 \%$ & 304 & $39,0 \%$ & 476 & $61,0 \%$ & 780 & $100 \%$ \\
\hline 40 a 49 anos & 433 & $62,0 \%$ & 265 & $38,0 \%$ & 698 & $100 \%$ & 283 & $40,7 \%$ & 413 & $59,3 \%$ & 696 & $100 \%$ \\
\hline 50 a 69 anos & 513 & $64,5 \%$ & 282 & $35,5 \%$ & 795 & $100 \%$ & 381 & $48,3 \%$ & 408 & $51,7 \%$ & 789 & $100 \%$ \\
\hline 70 anos ou mais & 90 & $67,7 \%$ & 43 & $32,3 \%$ & 133 & $100 \%$ & 57 & $42,9 \%$ & 76 & $57,1 \%$ & 133 & $100 \%$ \\
\hline \multicolumn{13}{|c|}{ Na Cidade } \\
\hline & \multicolumn{6}{|c|}{ Durante o dia } & \multicolumn{6}{|c|}{ Durante a noite $(*)$} \\
\hline & \multicolumn{2}{|c|}{ Seguro } & \multicolumn{2}{|c|}{ Inseguro } & \multicolumn{2}{|c|}{ Total } & \multicolumn{2}{|c|}{ Seguro } & \multicolumn{2}{|c|}{ Inseguro } & \multicolumn{2}{|c|}{ Total } \\
\hline 16 a 17 anos & 42 & $51,9 \%$ & 39 & $48,1 \%$ & 81 & $100 \%$ & 25 & $30,9 \%$ & 56 & $69,1 \%$ & 81 & $100 \%$ \\
\hline 18 a 24 anos & 294 & $44,3 \%$ & 370 & $55,7 \%$ & 664 & $100 \%$ & 161 & $24,2 \%$ & 503 & $75,8 \%$ & 664 & $100 \%$ \\
\hline 25 a 29 anos & 192 & $42,1 \%$ & 264 & $57,9 \%$ & 456 & $100 \%$ & 109 & $24,0 \%$ & 346 & $76,0 \%$ & 455 & $100 \%$ \\
\hline 30 a 39 anos & 321 & $41,2 \%$ & 459 & $58,8 \%$ & 780 & $100 \%$ & 186 & $23,8 \%$ & 594 & $76,2 \%$ & 780 & $100 \%$ \\
\hline 40 a 49 anos & 288 & $41,5 \%$ & 406 & $58,5 \%$ & 694 & $100 \%$ & 178 & $25,6 \%$ & 518 & $74,4 \%$ & 696 & $100 \%$ \\
\hline 50 a 69 anos & 336 & $42,5 \%$ & 455 & $57,5 \%$ & 791 & $100 \%$ & 218 & $27,8 \%$ & 565 & $72,2 \%$ & 783 & $100 \%$ \\
\hline 70 anos ou mais & 58 & $43,6 \%$ & 75 & $56,4 \%$ & 133 & $100 \%$ & 41 & $31,1 \%$ & 91 & $68,9 \%$ & 132 & $100 \%$ \\
\hline
\end{tabular}

(*) Diferença estatisticamente significante com uma probabilidade de $95 \%$.

Fonte: Pesquisa sobre as Condições de Vida e o Acesso das Pessoas a Serviços Públicos aqui na sua Região (FIGUEIREDO, SALLES, RIBEIR0 e BORGES, 2010).

O status socioeconômico também é muito utilizado na explicação do sentimento de insegurança. Segundo Skogan e Maxfield (1981), as pessoas com status socioeconômico mais baixo sentem-se menos seguras. Davis e Peixoto (2003), por outro lado, encontraram resultados contrários na região metropolitana de Belo Horizonte, ou seja, as pessoas com status socioeconômico mais alto têm maior percepção do risco de vitimização.

Conforme observamos na Tabela 3, as pessoas com maior nível de escolaridade tendem a se sentirem mais inseguras do que as de menor escolaridade, apesar dessa relação não ser linear. Os mais escolarizados apresentaram percentual mais alto de insegurança por se sentirem alvos mais atrativos para uma ocorrência criminal, uma vez que educação pode ser uma proxy para classe social e que alta escolaridade pode representar uma classe social mais alta. Isso significa que os mais abastados tendem a se 
sentir mais atrativos, por considerarem que ao se tornar vítimas de um assalto, por exemplo, podem render alto lucro ao ofensor (BORGES, 2011).

Tabela 3 - Sentimento de insegurança durante o dia e à noite por local, segundo a escolaridade

\section{No Bairro}

\begin{tabular}{|c|c|c|c|c|c|c|c|c|c|c|c|c|}
\hline \multirow[b]{3}{*}{ Analfabeto } & \multicolumn{6}{|c|}{ Durante o dia $(*)$} & \multicolumn{6}{|c|}{ Durante a noite $\left(^{*}\right)$} \\
\hline & \multicolumn{2}{|c|}{ Seguro } & \multicolumn{2}{|c|}{ Inseguro } & \multicolumn{2}{|c|}{ Total } & \multicolumn{2}{|c|}{ Seguro } & \multicolumn{2}{|c|}{ Inseguro } & \multicolumn{2}{|c|}{ Total } \\
\hline & 146 & $75,3 \%$ & & $24,7 \%$ & 194 & $100 \%$ & 103 & $53,4 \%$ & 90 & $46,6 \%$ & 193 & $100 \%$ \\
\hline Sabe ler/escrever & 20 & $62,5 \%$ & & $37,5 \%$ & & $100 \%$ & & $34,4 \%$ & 21 & $65,6 \%$ & 32 & $100 \%$ \\
\hline Ensino Fundamental Incompleto & 792 & $63,9 \%$ & 448 & $36,1 \%$ & 1240 & $100 \%$ & 557 & $45,1 \%$ & 678 & $54,9 \%$ & 1235 & $100 \%$ \\
\hline Ensino Fundamental Completo & 219 & $58,1 \%$ & 158 & $41,9 \%$ & 377 & $100 \%$ & 153 & $40,6 \%$ & 224 & $59,4 \%$ & 377 & $100 \%$ \\
\hline Ensino Médio Incompleto & 201 & $59,3 \%$ & 138 & $40,7 \%$ & 339 & $100 \%$ & 117 & $34,6 \%$ & 221 & $65,4 \%$ & 338 & $100 \%$ \\
\hline Ensino Médio Completo & 563 & $61,9 \%$ & & $38,1 \%$ & 910 & $100 \%$ & 351 & $38,6 \%$ & 559 & $61,4 \%$ & 910 & $100 \%$ \\
\hline Superior incompleto & 167 & $65,2 \%$ & & $34,8 \%$ & 256 & $100 \%$ & 98 & $38,3 \%$ & 158 & $61,7 \%$ & 256 & $100 \%$ \\
\hline Superior completo & 165 & $64,0 \%$ & 93 & $36,0 \%$ & 258 & $100 \%$ & 100 & $38,8 \%$ & 158 & $61,2 \%$ & 258 & $100 \%$ \\
\hline
\end{tabular}

Na Cidade

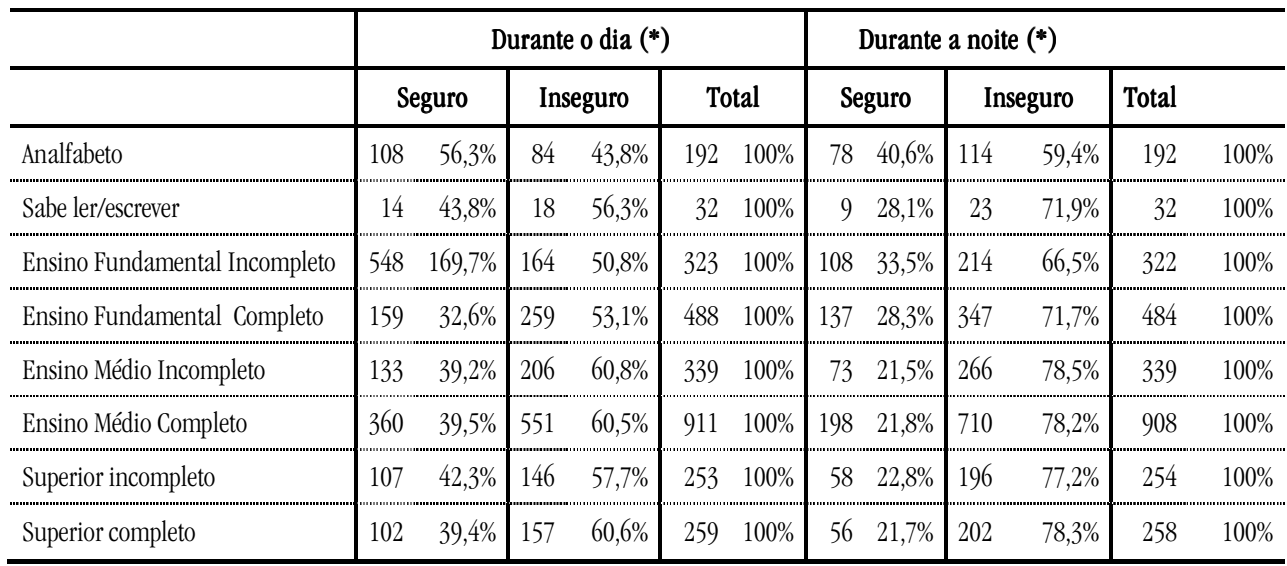

(*) Diferença estatisticamente significante com uma probabilidade de $95 \%$.

Fonte: Pesquisa sobre as Condições de Vida e o Acesso das Pessoas a Serviços Públicos aqui na sua Região (FIGUEIREDO, SALLES, RIBEIR0 e BORGES, 2010).

Tal como vimos com a escolaridade, a variável renda familiar per capita é uma variável importante no estudo do sentimento de insegurança. Analisando a Tabela 4, 
percebemos que os indivíduos cuja renda familiar per capita é de 3 salários mínimos ou mais apresentaram maiores percentuais de insegurança no bairro durante a noite e na cidade, durante 0 dia e à noite.

Tabela 4 - Sentimento de insegurança durante o dia e à noite por local, segundo faixa de renda familiar per capita em salários mínimos

\begin{tabular}{|c|c|c|c|c|c|c|c|c|}
\hline \multicolumn{9}{|c|}{ No Bairro } \\
\hline & \multicolumn{4}{|c|}{ Durante o dia $(*)$} & \multicolumn{4}{|c|}{ Durante a noite $\left(^{*}\right)$} \\
\hline & Seguro & Inseguro & \multicolumn{2}{|c|}{ Total } & Seguro & Inseguro & \multicolumn{2}{|c|}{ Total } \\
\hline Menos de $1 / 2 \mathrm{SM}$ & $668 \quad 61,1 \%$ & $426 \quad 38,9 \%$ & 1.094 & $100 \%$ & $444 \quad 40,7 \%$ & $648 \quad 59,3 \%$ & 1.092 & $100 \%$ \\
\hline 1/2 a $1 \mathrm{SM}$ & $719 \quad 62,4 \%$ & $434 \quad 37,6 \%$ & 1.153 & $100 \%$ & $473 \quad 41,1 \%$ & $678 \quad 58,9 \%$ & 1.151 & $100 \%$ \\
\hline $1 \mathrm{a} 2 \mathrm{SM}$ & $638 \quad 66,3 \%$ & $324 \quad 33,7 \%$ & 962 & $100 \%$ & $412 \quad 42,9 \%$ & $548 \quad 57,1 \%$ & 960 & $100 \%$ \\
\hline $3 \mathrm{SM}$ ou mais & $101 \quad 66,0 \%$ & $52 \quad 34,0 \%$ & 153 & $100 \%$ & $58 \quad 37,9 \%$ & $95 \quad 62,1 \%$ & 153 & $100 \%$ \\
\hline \multicolumn{9}{|c|}{$\mathrm{Na}$ Cidade } \\
\hline & \multicolumn{4}{|c|}{ Durante o dia $(*)$} & \multicolumn{4}{|c|}{ Durante a noite $\left({ }^{*}\right)$} \\
\hline & Seguro & Inseguro & \multicolumn{2}{|c|}{ Total } & Seguro & Inseguro & \multicolumn{2}{|c|}{ Total } \\
\hline Menos de $1 / 2 \mathrm{SM}$ & $445 \quad 40,9 \%$ & $643 \quad 59,1 \%$ & 1.088 & $100 \%$ & $272 \quad 25,0 \%$ & $815 \quad 75,0 \%$ & 1.087 & $100 \%$ \\
\hline $1 / 2$ a 1 SM & $507 \quad 44,0 \%$ & $646 \quad 56,0 \%$ & 1.153 & $100 \%$ & $301 \quad 26,2 \%$ & $849 \quad 73,8 \%$ & 1.150 & $100 \%$ \\
\hline $1 \mathrm{a} 2 \mathrm{SM}$ & $419 \quad 43,5 \%$ & $544 \quad 56,5 \%$ & 963 & $100 \%$ & $244 \quad 25,4 \%$ & $715 \quad 74,6 \%$ & 959 & $100 \%$ \\
\hline 3 SM ou mais & $60 \quad 39,5 \%$ & $92 \quad 60,5 \%$ & 152 & $100 \%$ & $36 \quad 23,7 \%$ & $11676,3 \%$ & 152 & $100 \%$ \\
\hline
\end{tabular}

(*) Diferença estatisticamente significante com uma probabilidade de $95 \%$.

Fonte: Pesquisa sobre as Condições de Vida e o Acesso das Pessoas a Serviços Públicos aqui na sua Região (FIGUEIREDO, SALLES, RIBEIR0 e BORGES, 2010).

Alguns estudiosos procuram abordar os efeitos de cor sobre o medo do crime, e normalmente verificam que os negros e pessoas de baixo status socioeconômico são os grupos que apresentam maior medo. Os estudiosos argumentam que a vulnerabilidade social desses grupos é um dos fatores mais importantes na explicação da relação entre cor e status socioeconômico e medo do crime (ROUNTREE, 1998). Outras pesquisas sugerem que a relação entre vitimização e medo pode estar condicionada à cor, com efeitos mais pronunciados nos brancos (CHIRICOS, HOGAN; GERTZ, 1997). De acordo com Skogan e Maxfield (1981), as diferenças de cor no que se refere ao medo do crime acontecem, em parte, por conta das diferenças de exposição ao crime: os negros de todas as idades têm mais chances de viverem em vizinhanças com altas taxas de crime do que os brancos. 
Segundo alguns pesquisadores, os negros estão em desvantagem em relação aos brancos. Eles são mais pobres, possuem menor grau de escolaridade e apresentam menor expectativa de vida (HENRIQUES, 2001), bem como, possuem maiores chances de vitimização (SOARES; BORGES, 2004) do que os brancos.

Os resultados da pesquisa (Gráfico7) mostram que as pessoas que se autodeclararam pardas foram as que mais apresentaram insegurança durante a noite, em seu bairro de moradia e na cidade. Já os brancos e os pretos foram os que demonstraram menos medo em seu bairro de moradia durante o dia.

Gráfico 7 - Sentimento de insegurança durante o dia e a noite por local, segundo a cor

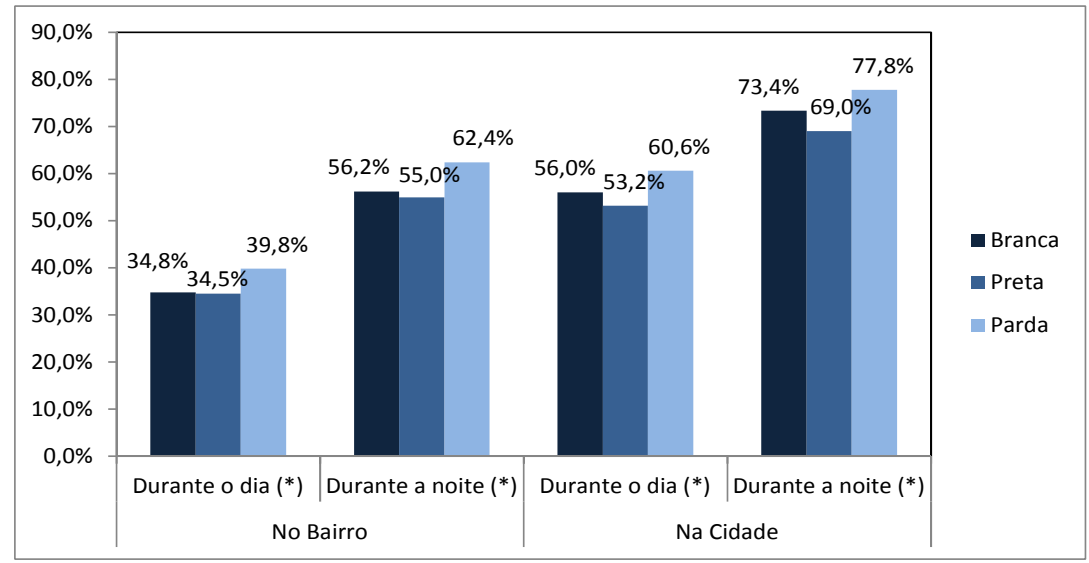

(*) Diferença estatisticamente significante com uma probabilidade de $95 \%$.

Fonte: Pesquisa sobre as Condições de Vida e o Acesso das Pessoas a Serviços Públicos aqui na sua Região (FIGUEIREDO, SALLES, RIBEIR0 e BORGES, 2010).

0 senso comum sugere que sofrer um delito é uma experiência que condiciona as percepções e crenças das pessoas. Já ter sido vitimizado pode ser um agravante do medo de frequentar determinados lugares ou simplesmente de sair de casa. Rountree (1998) mostraram que a vitimização prévia tem relação com o medo. No entanto, outros pesquisadores, tal como McGarrell, Giacomazzi e Thurman (1997), argumentam que 0 efeito da vitimização sobre o medo do crime é fraco. Analisando os resultados da pesquisa, podemos verificar que existe algum tipo de relação entre o sentimento de insegurança e a vitimização (Gráfico 8). As pessoas que experimentaram a vitimização no último ano anterior a pesquisa apresentaram maiores percentuais de insegurança durante o dia e à noite, no bairro de moradia e na cidade. 
Gráfico 8 - Sentimento de insegurança durante o dia e à noite por local, segundo vitimização

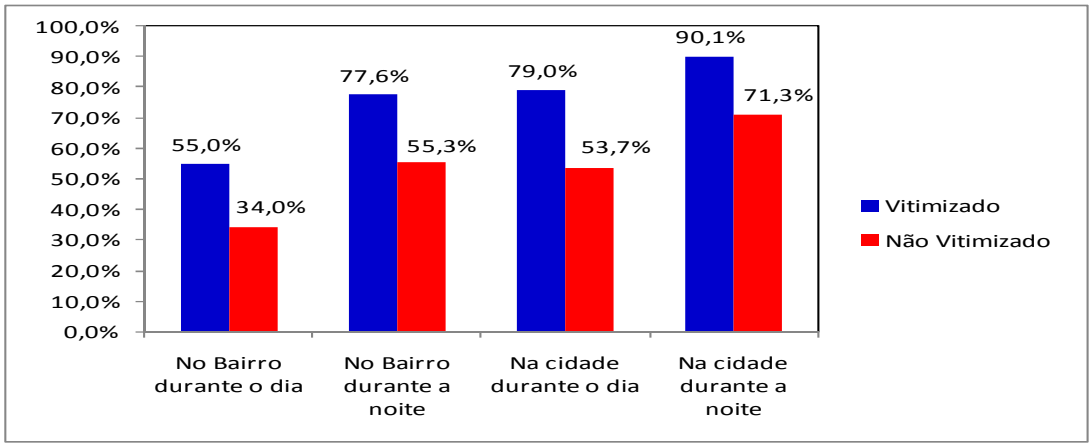

(*) Diferença estatisticamente significante com uma probabilidade de $95 \%$.

Fonte: Pesquisa sobre as Condições de Vida e o Acesso das Pessoas a Serviços Públicos aqui na sua Região (FIGUEIREDO, SALLES, RIBEIR0 e BORGES, 2010).

Por outro lado, Ferraro (1995) argumenta que a relação entre a vitimização prévia e o medo do crime depende do tipo de vitimização. Na Tabela 5, é possível verificar que o percentual de pessoas que se sente insegura é diferente segundo o tipo de crime no qual foram vitimizadas nos últimos 12 meses. As pessoas vitimizadas por roubo, ou seja, um crime violento contra o patrimônio se sentem mais inseguras do que aquelas que foram vitimizadas por furto, crime não violento contra o patrimônio. Esse resultado se repete para 0 sentimento de insegurança durante o dia e à noite, na cidade e no bairro de moradia. 
Tabela 5 - Sentimento de insegurança durante o dia e à noite por local, segundo vitimização por tipo de crime

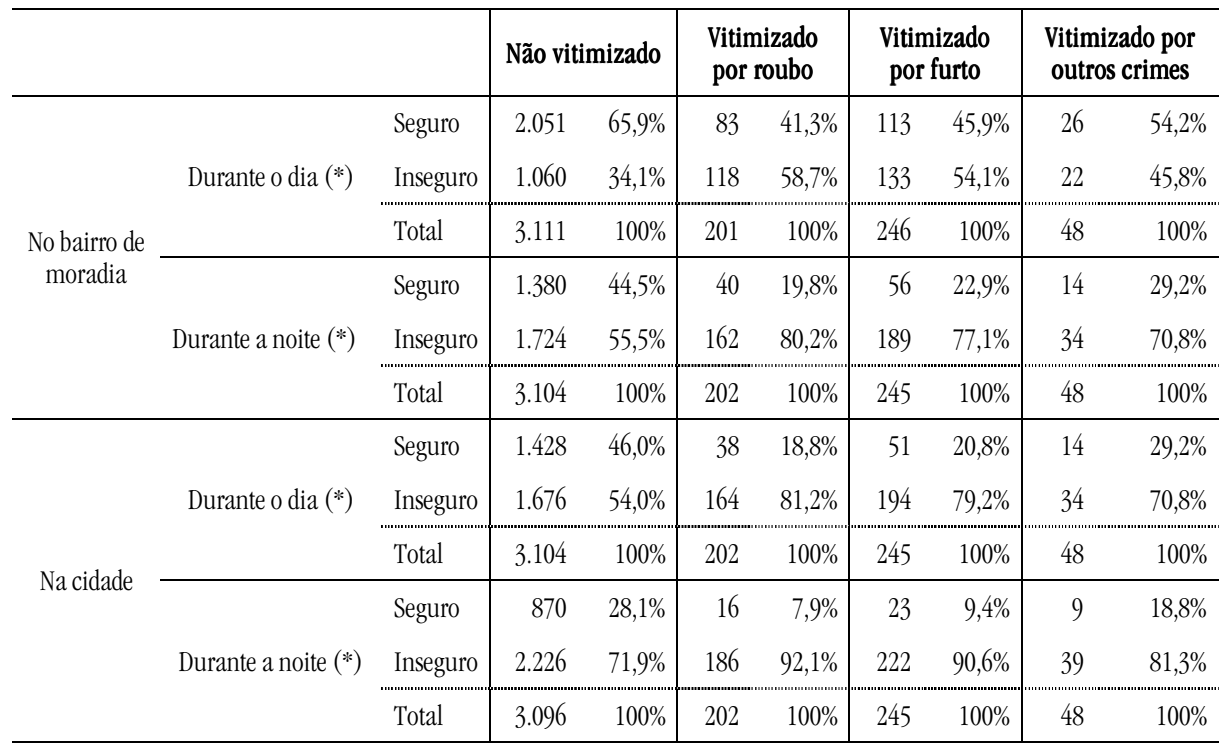

(*) Diferença estatisticamente significante com uma probabilidade de $95 \%$.

Fonte: Pesquisa sobre as Condições de Vida e o Acesso das Pessoas a Serviços Públicos aqui na sua Região (FIGUEIREDO, SALLES, RIBEIR0 e BORGES, 2010).

Recorrendo à análise de Regressão Logística ${ }^{4}$ para estudar o sentimento de insegurança durante o dia e à noite, no bairro de moradia e na cidade, podemos avaliar a razão de chances $(\mathrm{RC})$ de uma pessoa se sentir insegura, ao variarmos os níveis dos fatores explicativos. No Quadro 1 verificamos os resultados dos quatro modelos ${ }^{5}$.

\footnotetext{
${ }^{4} 0$ uso desta técnica para ajustar modelos estatísticos permite identificar quais fatores explicativos possibilitam interpretar adequadamente o perfil do grupo com maior risco/probabilidade de se sentir inseguro, utilizando outras variáveis escolhidas a partir de testes de qualidade do ajuste. Tal procedimento permite obter uma medida de como essas variáveis influenciam a probabilidade de uma pessoa se sentir insegura.

${ }^{5}$ Vale ressaltar que as variáveis cor e renda familiar per capita não foram significativas para nenhum dos modelos.
} 
Quadro 1 - Modelos de Regressão Logística para estimar a probabilidade de sentimento de insegurança

\begin{tabular}{|c|c|c|c|c|c|c|c|c|c|c|c|c|}
\hline & \multicolumn{6}{|c|}{ No Bairro } & \multicolumn{6}{|c|}{$\mathrm{Na}$ Cidade } \\
\hline & \multicolumn{3}{|c|}{ Durante o Dia } & \multicolumn{3}{|c|}{ Durante a Noite } & \multicolumn{3}{|c|}{ Durante o Dia } & \multicolumn{3}{|c|}{ Durante a Noite } \\
\hline & Coefic. & $\begin{array}{c}\mathrm{P}- \\
\text { Valor }\end{array}$ & $\begin{array}{l}\text { Razão de } \\
\text { Chances }\end{array}$ & Coefic. & $\begin{array}{l}\text { P- } \\
\text { Valor }\end{array}$ & $\begin{array}{l}\text { Razão de } \\
\text { Chances }\end{array}$ & Coefic. & $\begin{array}{l}\text { P- } \\
\text { Valor }\end{array}$ & $\begin{array}{l}\text { Razão de } \\
\text { Chances }\end{array}$ & Coefic. & $\begin{array}{l}\text { P- } \\
\text { Valor }\end{array}$ & $\begin{array}{l}\text { Razão de } \\
\text { Chances }\end{array}$ \\
\hline Intercepto & $-0,225$ & 0,132 & & 0,770 & 0,000 & & 1,000 & 0,000 & & 1,844 & 0,000 & \\
\hline Feminino & 0,330 & 0,000 & 1,39 & 0,242 & 0,001 & 1,27 & 0,381 & 0,000 & 1,46 & 0,324 & 0,000 & 1,38 \\
\hline Masculino & 0,000 & & 1,00 & 0,000 & & 1,00 & 0,000 & & 1,00 & 0,000 & & 1,00 \\
\hline 16 a 24 anos & $-0,321$ & 0,002 & 0,73 & 0,030 & 0,761 & 1,03 & $-0,327$ & 0,001 & 0,72 & $-0,101$ & 0,367 & 0,90 \\
\hline 25 a 39 anos & 0,076 & 0,362 & 1,08 & 0,131 & 0,114 & 1,14 & $-0,109$ & 0,194 & 0,90 & 0,023 & 0,806 & 1,02 \\
\hline 40 anos ou mais & 0,000 & & 1,00 & 0,000 & & 1,00 & 0,000 & & 1,00 & 0,000 & & 1,00 \\
\hline Vitimizado & 0,863 & 0,000 & 2,37 & 0,995 & 0,000 & 2,70 & 1,194 & 0,000 & 3,30 & 1,274 & 0,000 & 3,58 \\
\hline Não Vitimizado & 0,000 & & 1,00 & 0,000 & & 1,00 & 0,000 & & 1,00 & 0,000 & & 1,00 \\
\hline Norte / Centro-Oeste & 0,402 & 0,004 & 1,50 & 0,253 & 0,047 & 1,29 & 0,175 & 0,173 & 1,19 & 0,078 & 0,571 & 1,08 \\
\hline Nordeste & 0,699 & 0,000 & 2,01 & 0,549 & 0,000 & 1,73 & 0,683 & 0,000 & 1,98 & 0,447 & 0,000 & 1,56 \\
\hline Sudeste & 0,570 & 0,000 & 1,77 & 0,426 & 0,000 & 1,53 & 0,615 & 0,000 & 1,85 & 0,500 & 0,000 & 1,65 \\
\hline Sul & 0,000 & & 1,00 & 0,000 & & 1,00 & 0,000 & & 1,00 & 0,000 & & 1,00 \\
\hline $\begin{array}{l}\text { Fundamental } \\
\text { completo ou mais }\end{array}$ & 0,194 & 0,014 & 1,21 & 0,248 & 0,001 & 1,28 & 0,275 & 0,000 & 1,32 & 0,347 & 0,000 & 1,41 \\
\hline \begin{tabular}{|l|} 
Fundamental \\
incompleto ou menos
\end{tabular} & 0,000 & & 1,00 & 0,000 & & 1,00 & 0,000 & & 1,00 & 0,000 & & 1,00 \\
\hline
\end{tabular}

Fonte: Pesquisa sobre as Condições de Vida e o Acesso das Pessoas a Serviços Públicos aqui na sua Região (FIGUEIREDO, SALLES, RIBEIR0 e BORGES, 2010).

No que se refere à variável sexo, confirmamos para o Brasil os resultados encontrados em outros estudos (WARR, 1984; STAFFORD; GALLE, 1984), ou seja, as mulheres se sentem mais inseguras do que os homens, independente do horário e do local de avaliação.

Analisando as razões de uma pessoa se sentir insegura segundo a faixa etária, verificamos que as chances de um jovem com idade entre 16 e 24 anos se sentir inseguro é menor do que a de pessoas com 40 anos ou mais, com exceção da avaliação da insegurança no bairro durante a noite. A experiência de vitimização é outra variável interessante na análise da probabilidade de uma pessoa se sentir insegura. Apesar de haver controvérsia na literatura acerca do tipo de efeito que a vitimização causa sobre a insegurança das pessoas (BORGES, 2011), o que percebemos nesse estudo é que no Brasil ter sido vítima aumenta as chances de uma pessoa se sentir insegura, sobretudo à noite e na cidade. 
Em se tratando das Grandes Regiões, constatamos que os residentes da região Sul são os que se sentem menos inseguros, enquanto que os mais inseguros são os nordestinos. Apesar de não estarmos comparando as estimativas dos modelos com as estatísticas oficiais, gostaríamos de destacar que a Região Nordeste foi a que apresentou as maiores taxas de homicídio no Brasil entre 2005 e 2010 (WAISELFISZ, 2012). No que se refere à escolaridade, os modelos apresentados parecem confirmar a hipótese de que os indivíduos com status socioeconômicos mais elevados apresentam crenças de que são mais atrativos para uma ação criminosa, o que os leva a sentirem mais medo (BORGES, 2011).

Como vimos, uma fração significativa de brasileiros se sente insegura, seja durante o dia ou à noite, no bairro de residência ou na cidade. Esse sentimento pode afetar a qualidade de vida das pessoas, gerando na comunidade um sentimento compartilhado de deterioração da confiança, da coesão e do controle social. Com isso, o medo generalizado do crime contribui para o crescimento da criminalidade e pode ainda, do ponto de vista político, prejudicar o exercício da liberdade e da cidadania.

\section{CONSIDERAÇÕES FINAIS}

A centralidade que assumiu a questão da violência nos debates públicos, nas decisões políticas e na vida diária das pessoas parece estar em consonância com dois fatores principais: a incidência da criminalidade e o sentimento generalizado e difuso de medo do crime e da insegurança. Os resultados dessa pesquisa confirmam essa ideia. A estimativa de vitimização por algum delito nos últimos 12 meses encontrada neste estudo foi de $14 \%$ para o Brasil, sendo mais significativa nas capitais (20,6\%) em comparação com os municípios da periferia (15,3\%) e do interior (10,7\%). Cerca de $60 \%$ da população brasileira se sente insegurança ao andar pelas ruas do bairro de moradia durante a noite.

Para analisar o sentimento de insegurança, vamos nos apropriar do Modelo de Crenças de Perigo proposto por Borges (2011), que parte da ideia de que essas crenças são uma ligação entre a realidade e a imaginação, que conecta 0 conhecimento do indivíduo e suas experiências reais de vida, a partir das trocas com os outros indivíduos. Este modelo se refere à construção de crenças de que alguma coisa ou alguém é perigoso. Essas crenças podem ser estímulos à geração de respostas de alerta para a pessoa. Em outras palavras, o indivíduo passa a sentir medo do crime, insegurança e uma percepção de risco ao entrar em contato com alguma experiência que acredite poder gerar riscos, ainda que esta crença não seja verdadeira.

Partindo desta perspectiva proposta por Borges (2011), entendemos que o fato de as mulheres, os mais velhos e os mais educados se sentirem mais inseguros pode estar 
associado ao componente de atratividade, que é explicado pela crença de que a pessoa é um alvo atrativo para um potencial ofensor. Ainda seguindo este modelo, a experiência de vitimização, seja ela direta ou indireta, pode fazer com que o indivíduo acredite estar sempre sujeito a riscos, o que aumenta as suas "Crenças de Perigo" (BORGES, 2011). Desse modo, concluímos que o sentimento de insegurança é uma resposta emocional a símbolos que as pessoas associam ao crime. Essa associação é a crença de que certos símbolos representam o crime ou que podem gerar perigo para o indivíduo, e que essas crenças são mais intensas em algumas regiões brasileiras: Nordeste e Sudeste.

\section{REFERÊNCIAS}

BEATO, Cláudio; PEIXOTO, Betânia Totino; ANDRADE, Mônica Viegas. Crime, oportunidade e vitimização. Revista Brasileira de Ciências Sociais, São Paulo, v. 19, n. 55, p. 73-89, 2004.

BORGES, Doriam. O medo do crime na cidade do Rio de Janeiro: uma análise sob a perspectiva das crenças de perigo. Curitiba: APPRIS, 2011.

CHIRICOS, Ted; HOGAN, Michael; GERTZ, Marc. Racial composition of neighborhood and fear of crime. Criminology, Columbus, v. 35, n. 1, p. 107-129, 1997.

COHEN, Lawrence; FELSON, Marcus. Social change and crime rate trends: a routine approach. American Sociological Review, Aliso Viejo, Califórnia, v. 44, p. 588-608, 1979 .

COHEN, Lawrence; KLUEGEL James; LAND, Kenneth. Social Inequality and Predatory Criminal Victimization: An Exposition and Test of a Formal Theory. American Sociological Review 46:505-24, 1981.

CONKLIN, John. E. The Impact of Crime. New York: Macmillan, 1975.

COOK, Philip J. The demand and supply of criminal opportunities. In: TONRY, Michael; MORRIS, Norval (Ed.). Crime and justice. Chicago: The University of Chicago Press, 1986. v. 7.

DAVIS, Corinne; PEIXOTO, Betânia Totino. Medo e espaço urbano: uma análise da percepção do risco de vitimização local e não local. In: CONGRESSO BRASILEIRO DE SOCIOLOGIA, 11., 2003, Campinas. Anais... Campinas: SBS, 2003. p. 2-26.

DUBOW, Fred; MCCABE, Edward; KAPLAN, Gail. Reactions to Crime: A Critical Review of the Literature. Washington, D.C.: National Institute of Law Enforcement and Criminal Justice, US Government Printing Office, 1979. 
FELSON, Marcus; COHEN, Lawrence E. Human ecology and crime: a routine activity approach. Human Ecology, New York, v. 8, p. 389-406, 1980.

FERRAR0, Kenneth. Fear of crime: interpreting victimization risk. Albany: State University of New York Press, 1995.

FIGUEIRED0, Argelina. ; SALLES, Denise ; RIBEIR0, Carlos Antônio Costa; BORGES, Doriam. Relatório Final do Projeto Avaliação de Eficácia de Políticas Públicas Praticadas. (Relatório de Pesquisa), 2010.

HALE, C. Fear of Crime: A Review of the Literature. International Review of Victimology, n. 4, p. 79-150, 1996.

HENRIQUES, Ricardo. Desigualdade racial no Brasil: evolução das condições de vida na década de 90. Rio de Janeiro: Instituto de Pesquisa Econômica Aplicada, 2001. (Texto para Discussão, 807).

McGARRELL, Edmund F.; GIACOMAZZI, Andrew L.; THURMAN, Quint C. Neighborhood disorder, integration, and the fear of crime. Justice Quarterly, Omaha, v. 14, p. 479-500, 1997.

OVIEDO, Enrique; RODRÍGUEZ, Alfredo. Santiago, una ciudad con temor. Temas Sociales, n.26, 1999.

PIQUET, Leandro. Determinantes do crime na América Latina: Rio de Janeiro e São Paulo. São Paulo. São Paulo: World Bank, 1999.

ROUNTREE, Pamela Wilcox. A reexamination of the crime-fear linkage. Journal of Research in Crime and Delinquency, New York, v. 35, n. 3, p. 341-372, 1998.

SKOGAN, Wesley; MAXFIELD, Michael. Coping with crime. Beverly Hills: Sage, 1981.

SOARES, Gláucio Ary Dillon; BORGES, Doriam. A cor da morte. Ciência Hoje, São Paulo, v. 35, p. 26-31, 2004.

STAFFORD, Mark C.; GALLE, Omer R. Victimization Rates, Exposure to Risk, and Fear of Crime. Criminology 22: 173-185, 1984.

WAISELFISZ, Julio Jacobo. Mapa da Violência 2013. Mortes Matadas por armas de fogo. $1^{a}$ edição. Flacso Brasil, 2012. (Disponível em www.mapadaviolencia.org.br).

WARR, Mark. Public perceptions and reactions to violent offending and victimization. In: REISS JUNIOR, Albert J.; ROTH Jeffrey A. Understanding and preventing violence, consequences and control. Washington: National Research Council, 1994. v. 4, p. 1-66. 